Zhan, Y., Li, J., Wang, M., Ren, Y., \& Chen. H. (2012). Analysis on the applications of information technology in mathematics classroom teaching and its correlation with students' mathematics achievements in China. Journal of Educational Technology Development and Exchange, 5(1), 1-12.

\title{
Analysis on the Applications of Information Technology in Mathematics Classroom Teaching and its Correlation with Students' Mathematics Achievements in China
}

\author{
Yi Zhan \\ Jing Li \\ Mei Wang \\ Youqun Ren \\ Hong Chen \\ East China Normal University
}

\begin{abstract}
On account of the question of "how can teachers facilitate learning more efficiently with the help of information technology," this research is going to probe into the application of information technology in mathematics classroom teaching and its correlation with students' mathematics achievements in China. It is established in the data from "Research on the Correlation between Learning and Curriculum," a program funded by Ministry of Education of China, that technology in mathematics education is important. Through the analysis of data, this research first describes how sampling teachers apply information technology in mathematics classroom teaching (including playing PPT lecture notes, using subject teaching software, and employing Internet in class) as well as the differences in the data among cities and schools. Besides, it also explores the correlation between how teachers apply information technology to the mathematics classroom teaching and students' mathematics achievements.
\end{abstract}

Keywords: mathematics teaching, applications of information technology, students' achievements

\section{Introduction}

"How can teachers facilitate learning more efficiently under the assistance of information technology?" is the key in integrating information technology into courses. We believe that the ultimate goal of integrating information technology and courses is to facilitate learning efficiently, which means positive changes in students' academic achievements.
In 2009, Shanghai took part in PISA2009 test. In 2010, OECD announced the test results: Shanghai scored top marks in reading, mathematics, and science tests among 65 countries and regions involved. This result has brought strong astonishment to relevant media and educational circles at home and abroad. Some researchers believe it is reasonable that Chinese students are generally adept in taking tests. Yet, others hold the view that Shanghai is among first-tier cites in China and its educational resources and quality are 
superior to the rest; Shanghai students' marks of PISA2009 test cannot reflect the overall situation of Chinese students and education in China (Liu, 2011; Lu \& Zhu, 2011).

Bearing reflections on the results of PISA2009 of Shanghai and thinking on current educational situation in China in mind, the research group called "Research on the Correlation between Learning and Curriculum" (a program funded by Ministry of Education of China) conducted a survey study in China mainland, trying to find out how relevant factors, including the information technology use, influence student achievement.

\section{Literature Review}

By searching with keywords "information technology integration" in the database of China academic articles, the researchers found 677 corresponding articles from 2004 to 2011. We skimmed through these articles and then classified them into different categories according to the content (shown in Table 1).

Table 1. Literatures on "Information Technology Integration" in China

\begin{tabular}{lcc}
\hline Categories & Number & Percentage \\
\hline Theory Study & 261 & $38.5 \%$ \\
Resources development & 36 & $5.3 \%$ \\
Technology application & 11 & $1.6 \%$ \\
Teaching and learning model & 102 & $15.1 \%$ \\
Teacher education & 25 & $3.7 \%$ \\
Technology and Subject integration case & 198 & $29.2 \%$ \\
Others & 55 & $8.1 \%$ \\
\hline
\end{tabular}

As Table 1 showed, we found that scholars in China mainly focused on the theoretical study (38.5\%) and technology and subject integration cases (29.2\%). Besides, all these articles paid little attention to the relationship between information technology use and students achievement. Also, there was a lack of empirical study to reveals the state quo of information technology integration in classrooms in China (Li, 2012). Fortunately, the survey study conducted by "Research on the Relationship between Learning and Curriculum" research group provided an opportunity to fill in this gap.

\section{Research Method}

Because this study is based on the database that "Research on the Correlation between Learning and Curriculum" research group have collected, we will first introduce the research method of this countrywide survey study.

\subsection{Method of "Research on the Correlation between Learning and Curriculum"}

The sampling work of this survey study includes three levels: city sampling, school sampling, student, and teacher sampling. One provincial capital from Northeast China (city1), South China (city2), Southwest China (city3), Northwest China (city4), and East China (Shanghai) were examined under the survey. As for school sampling, samples are selected in the light of two dimensions: school locations (downtown districts or suburban counties) and running conditions (key schools, 
ordinary schools and schools with limited running conditions). Every two schools qualified for each of the above conditions are drawn at random, namely 12 schools from each city and altogether 60 . In the case of student and teacher sampling, two Junior Three classes ( 15 years old) of each school, altogether 120 classes, are sampled according to PISA Test standards. All the students and teachers of the selected classes and principals of schools participated in the survey study.

Principals, teachers, and students involved are required to complete a questionnaire respectively. In the light of TIMSS2007 and PISA analytical framework on principal, teacher, and student questionnaire and the questionnaire content, these questionnaires were designed with a combination of China's actual conditions. Students also take two tests that are based on the PISA 2003 items. All the questionnaires and test papers have been trialtested and modified before use.

Teachers involved are required to complete a teacher questionnaire. In the light of TIMSS2007 analytical framework on teacher questionnaire and the questionnaire content, teacher questionnaire in this research is designed with a combination of Chinese teachers' specialized characteristics, focusing on collecting practical application of teachers that have direct influence on students' learning capacity. The questionnaire includes three aspects: basic information, professional practice, and teaching activity. Besides, teachers' applications of information technology in classroom teaching are also incorporated in the "teaching activity" part. A total of 30 items is placed in the questionnaire while three of them are related to information technology usage in classroom teaching. The answer time for teachers to complete the questionnaire is not limited.

The participating students are required to finish the questionnaire, as well as problemsolving and mathematics test papers in order (within 90 minutes as a whole). The mathematics test is drawn from PISA2003 Test Database, including Change and Relationships, Quantity, Space, and Shape as well as Uncertainty, by which students' capabilities of Connection, Reflection, and Reproduction are investigated. The result of the survey can reflect students' academic achievements on mathematics in a comparatively comprehensive way. The test paper includes sixteen parts with 25 items in total and the completion time is one-hour.

A total of 581 teachers and 5066 students participated in this investigation. Consequently, the research group collected 60 school questionnaires, 581 teacher questionnaires, 5057 student questionnaires, 5055 problem-solving test papers, and 5060 mathematics test papers (Table 2).

Table 2. Sample Size

\begin{tabular}{lcccccc}
\hline \multicolumn{1}{c}{$\begin{array}{c}\text { Data Available on Each } \\
\text { Measure }\end{array}$} & \multicolumn{5}{c}{ Cities Surveyed } & \multirow{2}{*}{ Total } \\
\cline { 2 - 6 } & City 1 & City 2 & City 3 & City 4 & City 5 & \\
\hline General Problem Solving & 911 & 1,075 & 1,164 & 962 & 943 & 5,055 \\
Mathematics & 912 & 1078 & 1165 & 963 & 942 & 5,060 \\
Student Questionnaire & 910 & 1,079 & 1,166 & 964 & 938 & 5,057 \\
Teacher Questionnaire & 131 & 120 & 124 & 100 & 106 & 581 \\
Principal Questionnaire & 12 & 12 & 12 & 12 & 12 & 60 \\
\hline
\end{tabular}


According to PISA marking criteria, the research group first takes the form of two members marking independently and then checking by discussion to mark the test. In line with Partial Credit Model of Item Response Theory, software CONQUEST is operated to process analysis by evaluating subjects' capacity and test items' parameters. With equivalent to test parameters in PISA2003 report, the subjects' scores are re-estimated (Ren, Zhan, \& Wen, 2012).

\subsection{Method of This Study}

In this study, "how teachers apply information technology in classroom teaching," as well as "what is the relationship between information technology use and student achievement" are to serve as the research questions. Because mathematics and problem-solving test papers were collected, and mathematics was a national curriculum taught in every school, we chose it as the target subject. Therefore, the much more specific questions of this study are "how mathematic teachers apply information technology in classroom teaching" and "what is the relationship between information technology use and students mathematics achievement."

In this study, the researchers used a combination of quantitative and qualitative methods. We first analyzed the statistical data of information technology applications in mathematics classroom teaching. Second, a correlation analysis of information technology usage and students' mathematics grades were provided. After that, several mathematics teachers of some Shanghai junior middle school were picked at random to conduct the open-ended tracking interview. In that interview, teachers were presented with the data analysis results we have performed and asked their opinions on these results.
In order to find answers to the questions in this research, we made a second selection from those collected by the research group of "Research on the Correlation between Learning and Curriculum." In the second data sampling period, we first selected all the questionnaires completed by teachers and students, as well as all the mathematic test papers of students. Then, we retained the Junior Three teachers eligible for any of the following standards based on "or" logic:

- Teaching at least 1 class matching the class sampling under survey;

- Teaching Junior Three which may include two classes under survey; or

- Teaching classes from the whole school (including two classes under survey).

Altogether 56 teachers and 56 corresponding classes finally remained. Among these 11, 11, 12, 10, 12 teachers were from city1-4 and Shanghai respectively, including 18 from key schools, 23 from ordinary schools, and 15 from schools with limited running conditions.

Third, based on the need of the research, this thesis combines practical usage characteristics carried by Chinese teachers' community and defines information technology applied to the mathematics classroom teaching as "playing PPT lecture notes," "presenting teaching content with subject teaching software," and "employing Internet in the classroom." Therefore, we kept the items from the "general information" and 3 items from "teaching activity" of teacher questionnaire.

\section{Research Results}

4.1. Applications of Information Technology in Mathematics Classroom Teaching 


\subsubsection{Playing PPT Lecture Notes}

In general, sampling teachers choose "often" and "occasionally" (28.6\% and $46.4 \%$ respectively) in playing PPT lecture notes in the classroom teaching; "almost in every class" and "seldom" are less chosen $(5.4 \%$ and $12.5 \%$ respectively).

\subsubsection{Difference among Cities}

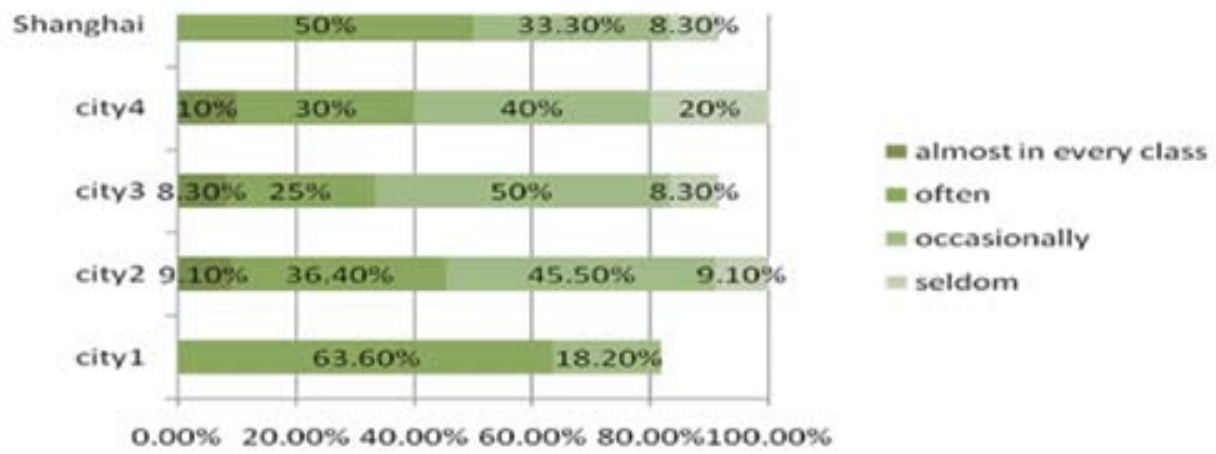

Figure 1. Difference of playing PPT lecture note in math teaching among cities (missing value $\mathrm{n}=5$ )

As Figure 1 shows, other than city 1 , more than $80 \%$ teachers in the other four cities use PPT to present teaching content in the classroom (including "almost in every class," "often," and "occasionally"). However, difference exists among cities with $9.1 \%$, $8.3 \%$ and $10 \%$ teachers from city 2 , city 3 , and city 4 respective make use of PPT in every class, whereas no such extreme case is found in Shanghai. There is no teacher in city 1 choosing "almost in every class" and "often;" those who choose "occasionally" and "seldom" account for $63.6 \%$ and $18.2 \%$ respectively. Nevertheless, there is no significant difference among different cities $\left(\chi^{2}=13.348, p>0.05\right)$.

\subsubsection{Difference among Schools}

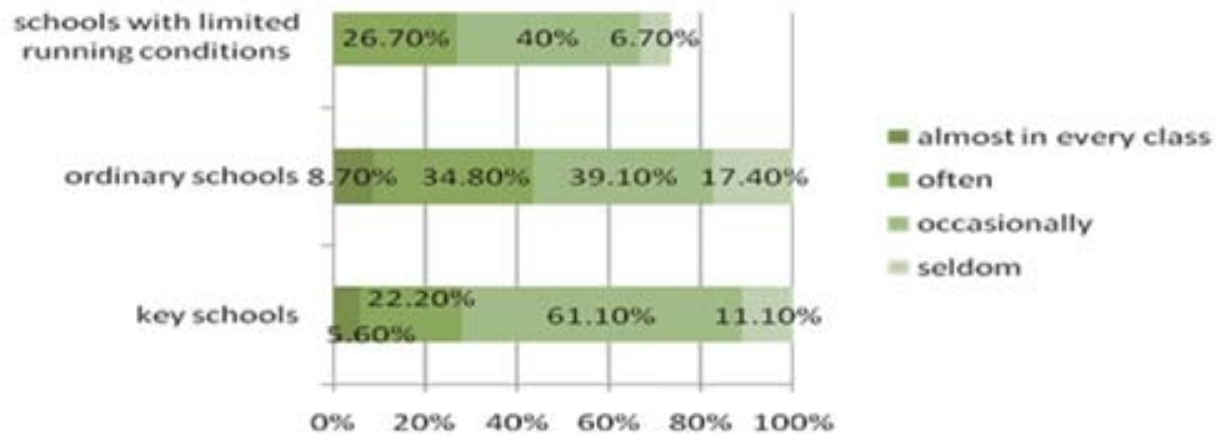

Figure 2. Difference of playing PPT in math teaching among schools (missing value $\mathrm{n}=4$ ) 
As Figure 2 shows, there is no significant difference in the amount of playing PPT lecture notes for Junior Three mathematics teachers in the classroom among different schools $\left(\chi^{2}=14.91, p>0.05\right)$. The PPT employment frequency of teachers from key schools forms an olive-shaped model; smaller at two ends and bigger in the middle. Teachers choosing "often" and "occasionally" account for about $80 \%$, which presents a reasonable and positive distribution. No teacher uses PPT "almost in every class" from schools with limited running conditions. The PPT employment frequency of teachers from ordinary schools is evenly distributed.

\subsubsection{Presenting Teaching Content with Subject Teaching Software}

Similar to the application of PPT, the majority of sampling teachers choose "often" and "occasionally" (19.6\%, 60.7\% respectively) in using subject teaching software in class while "almost in every class" and "seldom" only take up $3.6 \%$ and $10.7 \%$.

\subsubsection{Difference among Cities}

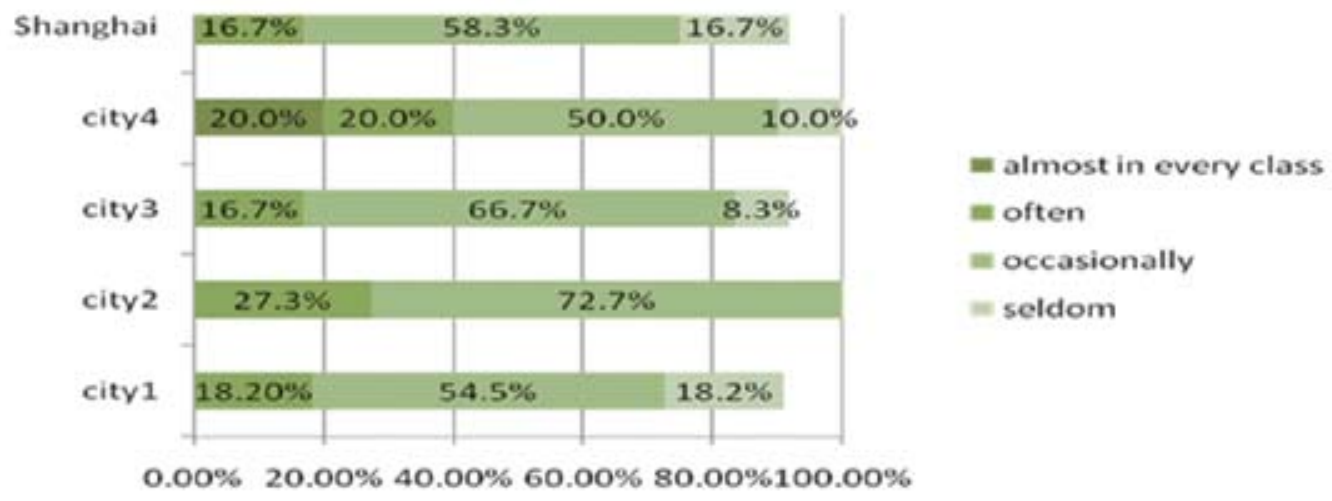

Figure 3. Difference of employing subject-teaching software in math teaching among cities

(missing value $n=3$ )

The frequency distribution of teachers employing subject-teaching software in class is almost the same as in Shanghai. City 1 and city 3 had no one choosing "almost in every class.". On the contrary, subjectteaching software is more widely used in city4's classroom teaching with up to $20 \%$ Junior Three Mathematics teachers using it in every class. Teachers in city 2 mainly cluster at "often" and "occasionally" with extreme cases (never and in every class) not showing up, which means the distribution is reasonable (Figure 3). It is displayed by the data that there is no significant difference among cities $\left(\chi^{2}=14.274, p=0.578>0.05\right)$. 


\subsubsection{Difference among Schools}

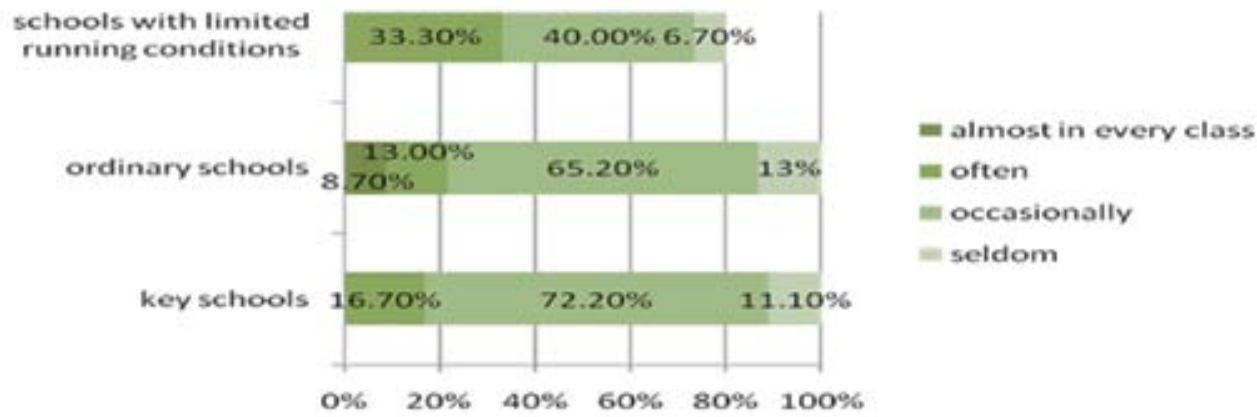

Figure 4. Difference in employing subject-teaching software in math teaching among schools (missing value $n=3$ )

As Figure 4 shows, most mathematics teachers choose to employ subject-teaching software in class. The proportion of Junior Three mathematics teachers using subjectteaching software in class exceeds $85 \%$ both in ordinary and in key schools, whereas only $73 \%$ in the schools with limited running conditions. Teachers from ordinary schools $(8.7 \%)$ use subject teaching software almost in every class while teachers from key schools mainly concentrate in occasional use (72.2\%). Nevertheless, there is no significant difference in overall distribution of subject teaching software in mathematics class among schools $\left(\chi^{2}=14.97, p=0.06>0.05\right)$.

\subsubsection{Internet Employment in Classroom}

It is suggested by the data that the frequency distribution of sampling teachers employing Internet in class from "almost in every class" to "seldom" is generally in a growing trend with $1.8 \%, 8.9 \%, 32.1 \%$ and $48.2 \%$, while nearly half of the teachers not using Internet in class.

\subsubsection{Difference among Cities}

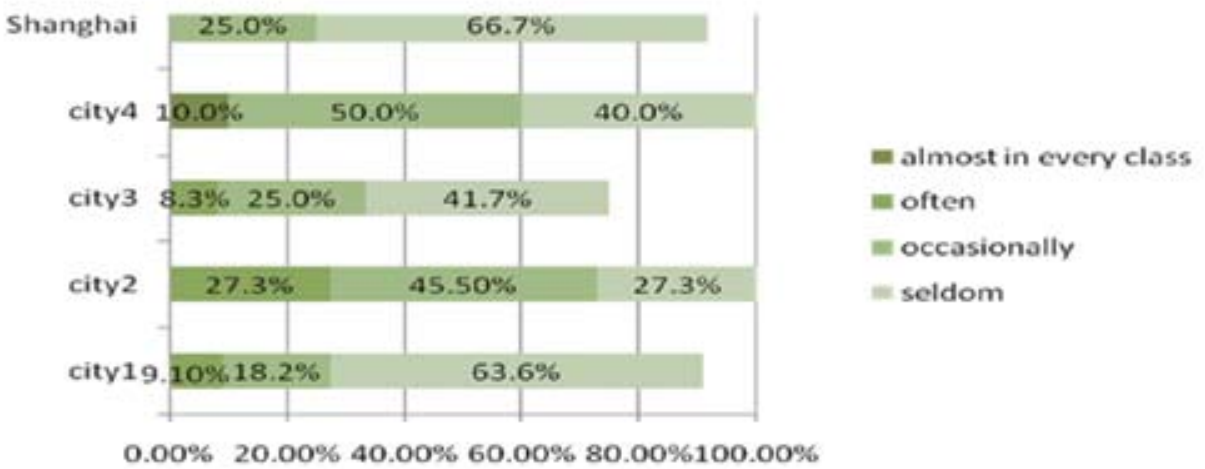

Figure 5. Difference in Internet employment in math teaching among cities (missing value $\mathrm{n}=5$ ) 
Although the data does not show a significance difference in Internet employment in mathematics class teaching among cities $\left(\chi^{2}=21.35, p=0.165>0.05\right)$, it is not difficult to find that employment frequency within each city varies. Generally speaking, Internet is not employed as widely as PPT and subjectteaching software. As shown in figure 5, more than $40 \%$ sampling teachers basically do not use Internet in class in Shanghai, city 1 , and city 3 whereas the percentage exceeds $60 \%$ in Shanghai and city 1 . Even in city 2 and city 4 where Internet is more broadly used, most teachers prefer employing Internet occasionally. The reasons behind this phenomenon remain to be studied.

\subsubsection{Difference among Schools}

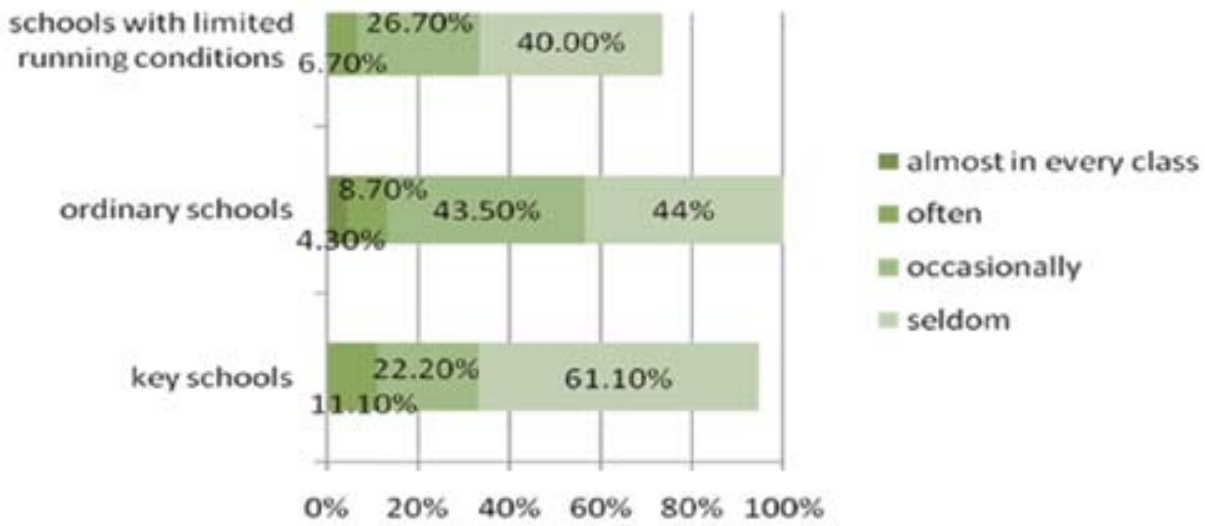

Figure 6. Difference in Internet employment in math teaching among schools (missing value $\mathrm{n}=5$ )

As Figure 6 shows, there is little significance in teachers employing Internet in class among different schools $\left(\chi^{2}=11.735\right.$, $p=0.163>0.05$ ). The amount of teachers who do not use Internet in key schools takes up $60 \%$ while more teachers in ordinary schools and schools with limited running conditions prefer using more $(11.1 \%)$. There is not a teacher who uses Internet in every class in any type of the schools. The four options distribute evenly in ordinary schools and $4.3 \%$ teachers use Internet in every class, whereas most teachers choose to use occasionally or seldom. In comparison, Internet is seldom employed in schools with limited conditions by having only $6.7 \%$ teachers use the Internet often.

\subsubsection{Information Technology Applications Difference among Teachers}

As "playing PPT lecture notes, using subject teaching-software and employing Internet in class" are significantly correlated with each other $(p<0.01$ when testing value is 0.01 ), we combined three activities ("almost in every class," "often," and "occasionally" are encoded as "use" and "seldom" as "not use") to give a general description about the difference in information technology applications in mathematics classroom teaching among teachers who differ in age, gender, and length of teaching. 
Little difference is found in information technology employment among teachers of different age and length of teaching $\left(\chi^{2}=1.396\right.$, $\left.p=0.498>0.05 ; \chi^{2}=0.799, p=0.85>0.05\right)$. The information technology usage rates for teachers between 20-30, 30-40, and over 40 years old account for $80 \%, 83.9 \%$, and $70 \%$ respectively.

As for length for teaching, young teachers do not show explicit passion for using information technology in class. The usage rate for new teachers is lower than that of grown teachers $(66.7 \%, 78.6 \%$, and $78.3 \%$ for years of 0-3, 6-15, and over 15years respectively) except teachers of 4-5 years have a high rate (usage rate is $100 \%$, only two teachers).

There is a concern that male teachers have higher usage rate over female teachers. All of 13 male teachers choose to employ information technology while nearly $30 \%$ of female teachers do not use information technology in class. There is a significant difference in information technology employment between male and female teachers $\left(\chi^{2}=4.617, p=0.032<0.05\right)$.

Table 3. Correlation Analysis of Information Technology Application and Students' Mathematics Achievements

\begin{tabular}{lllll}
\hline & \multicolumn{2}{l}{ Before controlling variables } & \multicolumn{2}{l}{ After controlling variables } \\
\cline { 2 - 5 } & $\begin{array}{l}\text { correlation } \\
\text { coefficients }\end{array}$ & $\begin{array}{l}\text { testing } \\
\text { values }\end{array}$ & $\begin{array}{l}\text { correlation } \\
\text { coefficients }\end{array}$ & $\begin{array}{l}\text { testing } \\
\text { values }\end{array}$ \\
\hline $\begin{array}{l}\text { Using PPT } \\
\text { Using subject teaching }\end{array}$ & 0.017 & 0.904 & 0.026 & 0.878 \\
$\begin{array}{l}\text { Software } \\
\text { Using internet in class }\end{array}$ & -0.019 & 0.892 & -0.086 & 0.612 \\
\hline
\end{tabular}

4.2. Correlation between Applications of Information Technology in Mathematics Classroom Teaching and Students, Mathematics Achievements

When doing encoding analysis in SPSS17.0, the missing values of 3 variables, playing PPT lecture notes, presenting by software, and employing Internet in class, are set as discrete missing value. The result shows (Table 2) that correlation coefficients between students' mathematics grades and teachers' employment of PPT, subject teaching software, and Internet in class are 0.017, -0.019 and -0.009 . Yet, testing values are
0.904, 0.892 and 0.950, all greater than 0.05, which means there is no significant linear pair wise correlation among each variable.

Under the condition of controlling variables such as teachers' gender, age, length of teaching, education background, city and region, the correlation coefficients, and testing values between mathematics grades and each variable are $0.026,-0.086$ and 0.150 respectively. Yet, testing values are 0.878 , 0.612 and 0.376 , all greater than 0.05 , which means there is still no significant correlation between grades and each variable. 


\subsection{Open-Ended Tracking Interview}

The tracking interview was conducted after we analyzed the data from the questionnaires. During the interview, teachers were presented with the data analysis results and asked to give their point of view.

It is observed from the statistics that teachers do not make use of PPT or subjectteaching software in every class. When interviewed about the reasons behind this phenomenon, some teachers pointed out that Junior Three is a period emphasizing general review while "subject-teaching software and Internet are much more suitable to impart new knowledge." Some teachers said that the content of Junior Three mathematics is mainly algebra and geometry among which "only geometry needs to be presented by software or Internet." Besides, they also think that most of the Junior Three mathematics teachers are experienced, but elders who "are good at teaching" but might "not be able to catch up with the technology advancement" is another reason behind the frequency of information technology application in classroom teaching.

In addition, the data also shows that teachers generally do not employ Internet in class. When interviewed, teachers acknowledged the role Internet has played in teaching. But, they also pointed out why they occasionally or seldom employ Internet in classroom teaching. One teacher said, "network is not as popular as PPT or subject teaching software" while most of interviewed teachers agree that "it is not convenient to use it in classroom teaching." However, although Internet is seldom used in classroom teaching, nearly all interviewed teachers search for resources on the Internet when preparing lessons.

Besides, some teachers pointed out that whether they choose to use a particular information technology in classroom teaching or not depend mainly on "whether this technology can really reduce my workload, help students to understand the content and improve their mathematics achievement or not."

\section{Conclusions and Discussion}

Today, information technology has entered the classrooms of most junior and primary schools in China and teachers have always been encouraged to apply information technology to teaching. However, it can be drawn in this research that despite discrepancy in many aspects such as teaching resources and teachers' qualifications among different cities and schools, there is little difference in applying information technology in class.

Meanwhile, whether information technology is applied in instruction really has no significant correlation with students' mathematics grades. This finding has confirmed the views of some researchers and educators who hold doubts and criticisms on the effects of applications of information technology in class. Nevertheless, we cannot make instant assertion that information has done no good to students. It is unwise to wholly abandon information technology in the context of education.

Therefore, subsequent research studies should focus on specific ways of applications, which are to be combined with subject content to conduct further research. Second, whether the use of information technology can benefit student learning or not is another important research topic. Besides, as we mentioned before, teachers have been using Internet during the lesson preparation stages, yet not during classroom teaching. Therefore, further study should take the affordance and restraints of different technology into consideration. 


\section{Reference}

Li, J. (2012). Research on the Status of Grade

9 Math Teachers' Use of Computers in the

Classroom and the Correlation between

It and the Students' Math achievements.

(Unpublished Master's thesis). East China

Normal University, Shanghai.

Liu, L. (2011). A critical Thinking on the Result of Shanghai 2009 PISA Test. China's Higher Education Evaluation, 2, 36-40.

Lu, J., \& Zhu, X. H. (2011). How to Look at the Result of Shanghai 2009 PISA Test Review of the Repercussion of the Result of Students from Shanghai, China First Take Part in International Evaluation. Shanghai Research on Education,1,17-19.

Ren, Y.Q., Zhan, Y., \& Wen, J. B. (2012). Achievement Scores and the Correlates of Chinese Students' Achievement: Evidence Beyond PISA (Programme for International Student Assessment) 2009. Paper Presented at the Annual Conference of the American Educational Research Association, April 13 - April 17, 2012, Vancouver, Canada. 


\section{Contact the Authors}

\section{Yi Zhan}

East China Normal University

Email: zhanyicaizi@163.com

\section{Jing Li}

East China Normal University

Email: stella_777@126.com

\section{Mei Wang}

East China Normal University

Email: wangm1980@gmail.com

\section{Youqun Ren}

East China Normal University

Email: yqren@admin.ecnu.edu.cn

\section{Hong Chen}

East China Normal University

Email: hchen@english.ecnu.edu.cn 